This item was submitted to Loughborough's Research Repository by the author.

Items in Figshare are protected by copyright, with all rights reserved, unless otherwise indicated.

\title{
Robust system state estimation for active suspension control in high-speed tilting trains
}

PLEASE CITE THE PUBLISHED VERSION

https://doi.org/10.1080/00423114.2014.901540

\section{PUBLISHER}

(C) Taylor \& Francis

\section{VERSION}

AM (Accepted Manuscript)

\section{PUBLISHER STATEMENT}

This work is made available according to the conditions of the Creative Commons Attribution-NonCommercialNoDerivatives 4.0 International (CC BY-NC-ND 4.0) licence. Full details of this licence are available at: https://creativecommons.org/licenses/by-nc-nd/4.0/

\section{LICENCE}

CC BY-NC-ND 4.0

\section{REPOSITORY RECORD}

Zhou, Ronghui, Argyrios C. Zolotas, and Roger M. Goodall. 2019. "Robust System State Estimation for Active Suspension Control in High-speed Tilting Trains". figshare. https://hdl.handle.net/2134/27062. 

available online: http://www.tandfonline.com/doi/abs/10.1080/00423114.2014.901540\#.

\title{
Robust system state estimation for active suspension control in high-speed tilting trains
}

\author{
Ronghui Zhou ${ }^{\mathrm{a} *}$, Argyrios Zolotas ${ }^{\mathrm{b}}$ and Roger Goodall ${ }^{\mathrm{c}}$ \\ ronghui.zhou@ge.com a.zolotas@ieee.org \\ ${ }^{a}$ Real-Time Controls and Instrumentation Laboratory, Global Research Center, GE, Shanghai 201203, \\ China; ${ }^{b}$ School of Engineering and Informatics, University of Sussex, Brighton BN1 9QT, UK; \\ ${ }^{c}$ Department of Electronic and Electrical Engineering, Loughborough University, Leicestershire \\ LE11 3TU, UK
}

\begin{abstract}
The interaction between the railway vehicle body roll and lateral dynamics substantially influences the tilting system performance in high-speed tilting trains, which results in a potential poor ride comfort and high risk of motion sickness. Integrating active lateral secondary suspension into the tilting control system is one of the solutions to provide a remedy to roll-lateral interaction. It improves the design trade-off for the local tilt control (based only upon local vehicle measurements) between straight track ride comfort and curving performance. Advanced system state estimation technology can be applied to further enhance the system performance, i.e. by using the estimated vehicle body lateral acceleration (relative to the track) and true cant deficiency in the configuration of the tilt and lateral active suspension controllers, thus to further attenuate the system dynamics coupling. Robust $H_{\infty}$ filtering is investigated in this paper aiming to offer a robust estimation (i.e. estimation in the presence of uncertainty) for the required variables, In particular, it can minimise the maximum estimation error and thus be more robust to system parametric uncertainty. Simulation results illustrate the effectiveness of the proposed schemes.
\end{abstract}

Keywords: active secondary suspension control; robust state estimation; tilt control; integrated suspension control

\section{Introduction}

Tilting trains operate at higher speeds compared to conventional trains, without the need to upgrade the rail infrastructure. The idea is straightforward, i.e. tilting the vehicle body inwards on the curves in the track to compensate for the increased lateral acceleration perceived by passengers at higher speeds.[1] Early passive tilting trains relied on the natural pendulum motion laws which introduced safety issues, while active tilting trains most commonly use a tilt mechanism driven by an actuator to tilt the vehicle body [2] (a schematic representation can be seen in Figure 1(a), which is an end-view of Swedish X2000 tilting train). In particular, tilting has become standard technology that is employed in a number of high-speed trains worldwide.

For the tilting control system, most providers use the so-called 'precedence' tilt control approach which is based upon providing tilt command from the preceding vehicle.[2] Its 


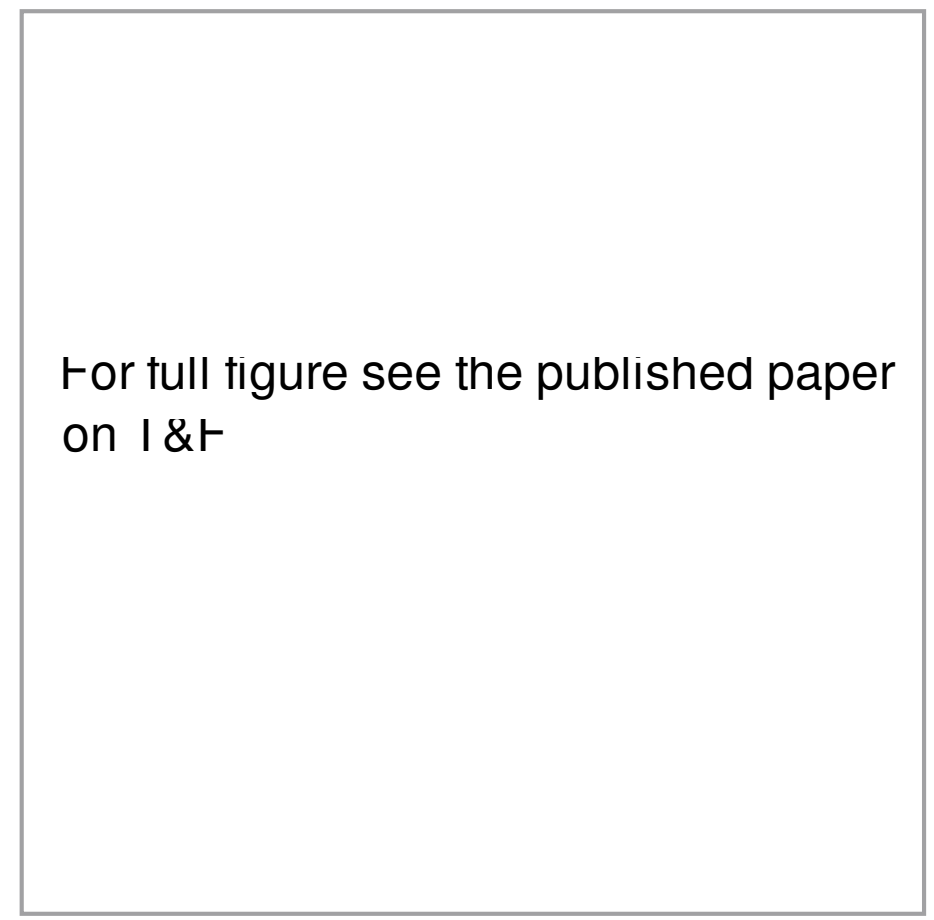

Figure 1. Tilting system and control. (a) Schematic of rail passenger vehicle with tilt mechanism. (b) Precedence tilt control approach.

schematic diagram is shown in Figure 1(b). More recently, ALSTOM developed a command driven controller referred to 'anticipative tilt control',[3] a solution that integrates the vehicle measurement with information from an onboard track database, hence providing the required track information to the tilt controller. Research work described in $[4,5]$ proposed several advanced tilt control approaches based on local, i.e. per vehicle, body signals that do not require precedence information, the aim being to provide a simpler system and more straightforward approach in terms of failure detection. It also benefits the tilt action of the leading vehicle which usually provides the precedence information but cannot take advantage of it itself.

However, due to the dynamic interaction between roll and lateral modes of the railway vehicle body, there is a limit to the level of transition performance improvement that can be achieved with the local tilt control. Moreover, tilting trains run at a higher speed on the same rail infrastructure compared to non-tilting trains, which deteriorates ride-quality performance on straight track and introduces a trade-off, for the tilting controller, between curving performance and straight track ride quality. In this context, the addition of a secondary lateral actuator and its integration with tilt control are largely discussed in [6]. The straight track ride quality and tilt performance are significantly improved with the lateral-tilt integrated active suspension configuration. In particular, the estimator-based decoupling (EBD) control, 
with the estimated vehicle body lateral acceleration and true cant deficiency (TCD) (these two quantities are unaffected by the suspension interaction) offered improved performance compared to the classical control approach, in which the lateral active suspension can purely deal with the lateral irregularity without increasing the lateral curving deflection, while the tilt action can be based on TCD.

Various model-based state estimation methodologies can be employed as virtual sensors to estimate the quantities which are often not readily available and cannot be easily and economically measured in practice. The Kalman filter has been intensively studied in [7] for estimation of the state variables, particularly of the wheelset relative to the track such as lateral displacement and yaw angle which are needed for active steering control. Further, a nonlinear Kalman filter approach was proposed to improve the robustness of the estimation to accommodate vehicle speed variation. The multiple model approach is discussed in [8], which enables a wide variety of adaptive estimation to be used under not only parameter changes but also model structure changes. It intensively enhances the robustness of the system state estimation technology. A robust extended Kalman filter is proposed in [9], where model uncertainty is taken into account and compared with the standard extended Kalman filter by simulation and experiment.

In this paper, $H_{\infty}$ filtering is considered to offer robust optimal estimation. The method minimises the maximum estimation error and aims to offer more robust solutions to system parametric uncertainty compared to a Kalman filter. The simulation results illustrate the effectiveness of the proposed estimator-based system. The remainder of this paper is organised as follows: Section 2 presents the tilting railway vehicle modelling which includes the vehicle lateral and roll dynamics. Section 3 summarises the tilt control performance assessment criteria. Integrated tilt with active lateral secondary suspension design with classical control configuration is presented in Section 4, while Section 5 discusses the details on the $H_{\infty}$ filter design, robust state estimation, and also gives a short summary on the performance assessment of the estimator-based control. This is followed by simulation results and discussion. Conclusions are discussed in the last section. Note that, although the scope of the paper focuses on the robust state estimation for control, the discussion here can be further extended to fault detection and tolerance field.

\section{Tilting railway vehicle modelling}

Figure 2 presents the diagram of the end-view model for the tilting train with the tilting bolster. The model was originally presented in [4], but without the lateral actuator. This model was extended in [6] to include the lateral actuator as a replacement for the lateral secondary suspension damper. Both the lateral and roll dynamics of the vehicle body and bogie are presented. The vertical dynamics are ignored but the roll effect arising from the vertical airspring suspension is included. An anti-roll bar system, the end moment effect (due to the movement of the body centre of gravity), and the translation and rotation of these reference axes associated with curves are all depicted in the model.

The tilt actuation system is modelled as a position servo in series with a mechanism which gives $3.5 \mathrm{~Hz}$ bandwidth and 50\% damping (it is a reasonable approximation because tilting is a low bandwidth action). Since, in this study, the focus is on the behaviour of the roll and lateral motion of the vehicle, the effect of the wheelset dynamics is incorporated simply by using a second-order low pass filter with $5 \mathrm{~Hz}$ cutoff frequency and $20 \%$ damping (wheelset dynamics do not affect the tilt action and in general the main behaviour of the secondary suspension, hence the vehicle passenger compartment). In this study, another actuator $\left(F_{\mathrm{a}}\right)$ is incorporated between the vehicle body and tilting bolster in the lateral direction. Ideal 


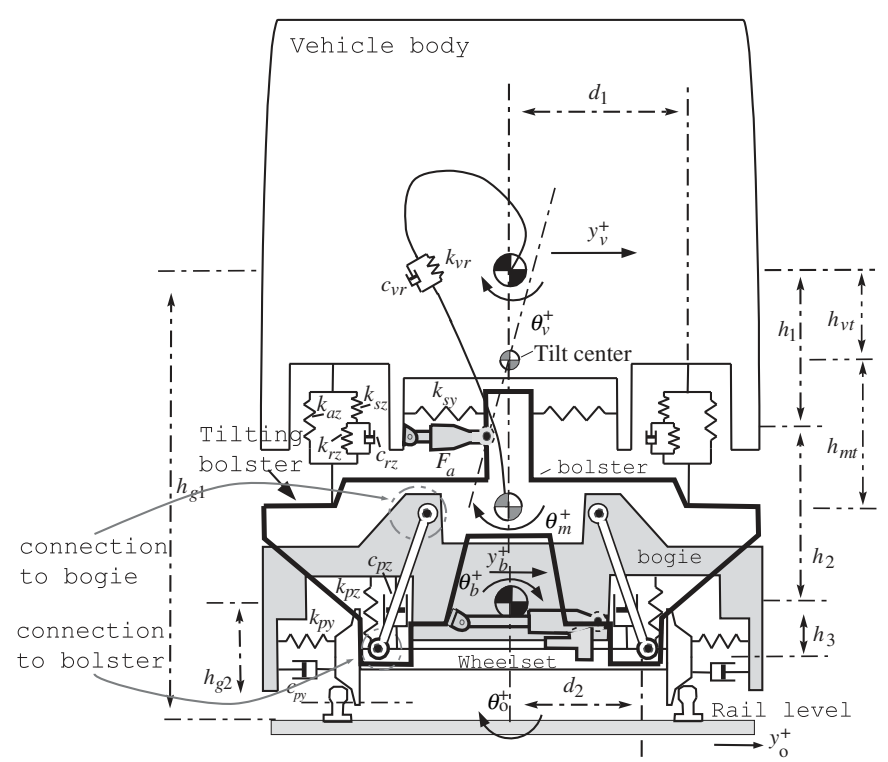

Figure 2. Tilting railway vehicle (end view).

actuation is used for the controller design, but a variety of technologies could be modelled, e.g. electro-mechanical, hydraulic and magnetic actuators.[10] The numerical equations for the integrated tilting bolster and active lateral secondary suspension are given below, and the parameters are listed in Appendix 1, which are typical values for a modern high-speed tilting train.

Body lateral and roll dynamics:

$$
\begin{aligned}
m_{v} \ddot{y}_{v}= & -2 k_{s y} y_{v}+2 k_{s y} h_{1} \theta_{v}+2 k_{s y} y_{b}+2 k_{s y} h_{2} \theta_{b}-\left(2 h_{m t} k_{s y}-m_{v} g\right) \theta_{m} \\
& +m_{v} g \theta_{0}-\frac{m_{v} v^{2}}{R}-m_{v} h_{g 1} \ddot{\theta}_{0}+F_{\mathrm{a}}, \\
i_{v r} \ddot{\theta}_{v}= & \left(2 h_{1} k_{s y}+m_{v} g\right) y_{v}-\left[k_{v r}+2 h_{1}{ }^{2} k_{s y}+2 d_{1}{ }^{2}\left(k_{a z}+k_{s z}\right)\right] \theta_{v} \\
& -2 h_{1} y_{b}\left(k_{s y}+m_{v} g\right)+\left(k_{v r}+2 d_{1}{ }^{2} k_{a z}-2 h_{1} h_{2} k_{s y}\right) \theta_{b}-c_{v r} \dot{\theta}_{v} \\
& +c_{v r} \dot{\theta}_{b}+2 k_{s z} d_{1}{ }^{2} \theta_{r}+\left(k_{v r}+2 d_{1}{ }^{2} k_{a z}+2 k_{s y} h_{1} h_{m t}\right) \theta_{m}+c_{v r} \dot{\theta}_{m} \\
& -i_{v r} \ddot{\theta}_{0}-F_{\mathrm{a}} h_{1} .
\end{aligned}
$$

Bogie lateral and roll dynamics:

$$
\begin{aligned}
m_{b} \ddot{y}_{b}= & 2 k_{s y} y_{v}-2 h_{1} k_{s y} \theta_{v}-2\left(k_{s y}+k_{p y}\right) y_{b}-2\left(h_{2} k_{s y}-h_{3} k_{p y}\right) \theta_{b} \\
& -2 c_{p y} \dot{y}_{b}+2 h_{3} c_{p y} \dot{\theta}_{b}+2 k_{p y} y_{w}+2 c_{p y} \dot{y}_{w}+2 h_{m t} k_{s y} \theta_{m}+m_{b} g \theta_{0} \\
& -\frac{m_{b} v^{2}}{R}-m_{b} h_{g 2} \ddot{\theta}_{0}-F_{\mathrm{a}}, \\
i_{b r} \ddot{\theta}_{b}= & 2 h_{2} k_{s y} y_{v}+\left[k_{v r}-2 h_{2} h_{1} k_{s y}+2 d_{1}^{2}\left(k_{a z}+k_{s z}\right)\right] \theta_{v}-2\left[h_{2} k_{s y}-h_{3} k_{p y}\right] y_{b} \\
& -\left(k_{v r}+2 h_{2}{ }^{2} k_{s y}+2 h_{3}{ }^{2} k_{p y}+2 d_{2}{ }^{2} k_{p z}+2 d_{1}{ }^{2} k_{a z}\right) \theta_{b}+c_{v r} \dot{\theta}_{v}+2 h_{3} c_{p y} \dot{y}_{b} \\
& -\left(c_{v r}+2 d_{2}{ }^{2} c_{p z}+2 h_{3}{ }^{2} c_{p y}\right) \dot{\theta}_{b}-2 k_{s z} d_{1}{ }^{2} \theta_{r}-2 h_{3} k_{p y} y_{w}-2 h_{3} c_{p y} \dot{y}_{w} \\
& -\left(k_{v r}+2 d_{1}{ }^{2} k_{a z}-2 k_{s y} h_{2} h_{m t}\right) \theta_{m}-c_{v r} \dot{\theta}_{m}-i_{b r} \ddot{\theta}_{0}-F_{\mathrm{a}} h_{2} .
\end{aligned}
$$


Tilting actuation system effect:

$$
\frac{\theta_{m}}{\theta_{m_{i}}}(s)=\frac{483.6}{s^{2}+22 s+483.6}
$$

Wheelset dynamics effect:

$$
\frac{y_{w}}{y_{0}}(s)=\frac{987}{s^{2}+12.57 s+987} .
$$

An additional state is used in the air spring model, in this case in the roll mode because as mentioned earlier this is where the airspring effects are included:

$$
\dot{\theta}_{r}=c_{r z}^{-1}\left(\theta_{r}\left(k_{s z}+k_{r z}\right)+k_{s z} \theta_{v}+k_{r z}\left(\theta_{b}+\theta_{m}\right)+c_{r z}\left(\dot{\theta}_{b}+\dot{\theta}_{m}\right)\right) .
$$

The system state space form is presented below, having two inputs, i.e. the tilt angle command and the lateral actuator force command $(u)$, states $(x)$ and track disturbances $(w)$ :

$$
\begin{aligned}
& \dot{x}=A x+B u+\Gamma \omega, \\
& y=C x+D u+v,
\end{aligned}
$$

where $x=\left[y_{v} \theta_{v} y_{b} \theta_{b} \dot{y}_{v} \dot{\theta}_{v} \dot{y}_{b} \dot{\theta}_{b} \theta_{r} y_{w} \dot{y}_{w} \theta_{m} \dot{\theta}_{m}\right]^{\mathrm{T}} ; \quad u=\left[\theta_{m_{i}} F_{\mathrm{a}}\right]^{\mathrm{T}}$ and $\omega=\left[R^{-1} \dot{R}^{-1} \theta_{0} \dot{\theta}_{0} \ddot{\theta}_{0} y_{0}\right]^{\mathrm{T}}$. The system is dynamically complex with strong coupling between the lateral and roll modes. The vehicle model and control system are tested with specific track inputs including both deterministic (low frequency) and stochastic (higher frequency) track features. The deterministic track used is a curved track with radius of $1200 \mathrm{~m}$ and a maximum track cant angle $\left(\theta^{\circ}\right)$ of $5.84^{\circ}$, with a $150 \mathrm{~m}$ transition at the start and end of the steady curve (it is designed for a normal vehicle with curving speed $45 \mathrm{~m} / \mathrm{s}$, while the curving speed increases to $58 \mathrm{~m} / \mathrm{s}$ with active tilt in this study). The stochastic track inputs represent the irregularities in the track alignment on both straight track and curves, and these were characterised by an approximate spatial spectrum equal to $\left((2 \pi)^{2} \Omega_{l} v^{2} / f\left(\mathrm{~m}^{2} /(\right.\right.$ cycle $\left./ \mathrm{m})\right)$ with lateral track roughness $\left(\Omega_{l}\right)$ of $0.33 \times 10^{-8}$.[4] More details on the modelling of the tilting railway vehicle and the track can be found in [5].

\section{Active suspension design requirements}

The active suspension design is a multi-objective optimisation process which needs to minimise the body acceleration on a straight track, consider the constraints for suspension deflection and system stability, and optimise the tilting performance on curved track, particularly at the transitions. The controller design for the dual-actuator system needs to meet both tilting and active lateral suspension performance requirements. Two main design criteria are involved:

- Deterministic performance criterion (with respect to the curved track):

Maintaining appropriate curve transition comfort level for standing and seated passengers is quantified by the $P_{c t}$ value which provides the percentage of (both standing and seated) passengers who feel uncomfortable during the curve transition, and can be calculated using the vehicle body lateral acceleration, lateral jerk and roll rate.[11] Moreover, the tilt controller assessment also relies upon identifying how the tilting vehicle would ideally perform on the transition from straight to curved track and then quantifying the 
deviation of the actual response compared with the identified ideal response. Associated with performance improvement is the constraint on lateral suspension deflection, which should not exceed the maximum allowed requirement before bump stops are reached, i.e. $\pm 60 \mathrm{~mm}$ is used here, which is a typical value for the lateral suspension deflection that is available.

- Stochastic performance criterion (with respect to the straight track):

Maximising the ride quality in response to track irregularities on straight track (stochastic criterion). Straight-track ride quality of the tilting train should degrade no more than 7.5\% [12] compared to the non-tilting train equivalent at the higher speed enabled by the tilting action, but the aim should be to minimise passenger lateral acceleration measurement (assessed by its root mean square (RMS) value) by means of the lateral actuator, i.e. in addition to improving the tilt system response.

\section{Tilting control design with integrated active lateral secondary suspension}

The main performance requirements for the tilt control system [2] can be summarised:

(i) to provide a comfortable response during curve transitions;

(ii) to maintain the straight track ride quality within acceptable limits.

Based on the vehicle dynamic modelling, the interaction between vehicle lateral and roll dynamics significantly affects tilt control performance on both curved track and straight track.

As described in [6], and as shown in Figure 3, the classical decentralised control (based on local per vehicle sensors) attempts to control the vehicle lateral and roll dynamics in two single input single output loops, in which the effective cant deficiency (ECD) and measured vehicle body lateral acceleration are used for tilt control and the lateral actuator (ride quality remedial action) control, respectively. Lateral actuator control loop is the inner loop and designed firstly because it is a high-bandwidth loop that responds to the high-frequency track irregularity $(2-10 \mathrm{~Hz})$, being faster than the tilting action (for which the bandwidth is below $1 \mathrm{~Hz})$.

$E C D$ :

$$
\theta_{d m}=-k_{1} \frac{\ddot{y}_{v m}}{g}-k_{2} \theta_{m}
$$

where $\theta_{m}$ is the actuator roll angle, $\ddot{y}_{v m}$ is the measured body lateral acceleration:

$$
\ddot{y}_{v m}=\frac{v^{2}}{R}-g\left(\theta_{0}+\theta_{v}\right)+\ddot{y}_{v}
$$

$k_{1}$ and $k_{2}$ are set to 0.75 and 0.25 , respectively, for $75 \%$ partial tilt compensation (note that, although the lateral acceleration could be fully compensated, in practice it is normal to only compensate for some proportion, and $75 \%$ is typical). The vehicle forward speed used in the simulation is $58 \mathrm{~m} / \mathrm{s}$.

The complementary filter skyhook damping control [13] combined with the integral of the lateral secondary suspension deflection is designed for the lateral actuator control, which has the function to improve the lateral ride quality while keeping the deflection within the required limit to avoid the lateral bump stop (i.e. $60 \mathrm{~mm}$ ).[14] A proportional-integral controller is designed for the tilting control. 
This is an Author's Original Manuscript of an article published by Taylor \& Francis Group in Vehicle System Dynamics: International Journal of Vehicle Mechanics and Mobility available online: http://www.tandfonline.com/doi/abs/10.1080/00423114.2014.901540\#.

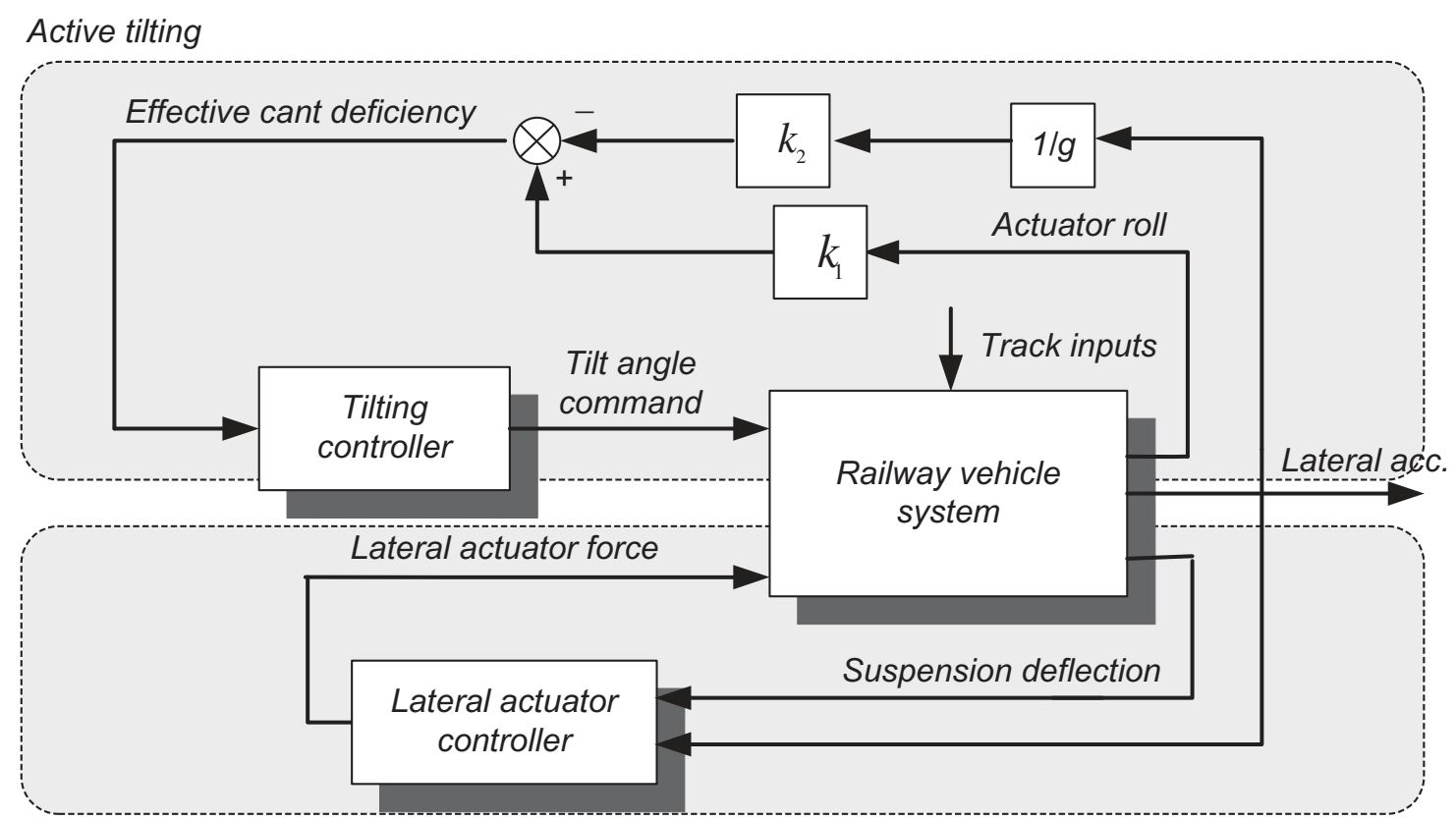

Active lateral suspension

Figure 3. Decentralised control for the integrated tilt and active lateral secondary.

\section{Robust state estimation and estimator-based control}

The more effective feedback signal for the lateral actuator control is the vehicle body lateral acceleration $\left(\ddot{y}_{v}\right)^{1}$. Unfortunately, a real lateral accelerometer also measures the curving acceleration, and so this signal has to be derived. Use of this signal means that the lateral active suspension can purely deal with the lateral irregularity without increasing the lateral suspension deflection during curving. The different way of deriving the curving acceleration experienced on the vehicle body, which is unaffected by the suspension dynamic interactions, is to use the, so-called, TCD [5]:

$$
\theta_{t d m}=\frac{v^{2}}{g \hat{R}}-\left(\hat{\theta}_{0}+\hat{\theta}_{m}\right),
$$

where $\hat{R}, \hat{\theta}_{0}$ and $\hat{\theta}_{m}$ are the estimated quantities of track curvature, track cant angle and body tilt angle, respectively. It is worth mentioning that the TCD given by Equation (12) is arranged to Equation (13) such that it provides $75 \%$ tilt compensation. Note that the compensation factor in (13) is set to 0.78 to accommodate the remaining $25 \%$ of uncompensated acceleration on the vehicle body, which forces the body to roll slightly out compared to the mechanism.

$$
\theta_{t d m}=0.78 \frac{v^{2}}{g \hat{R}}-\left(0.78 \hat{\theta}_{0}+\hat{\theta}_{m}\right)
$$

The combination of body lateral acceleration $\left(\ddot{y}_{v}\right)$ and TCD as the feedback signal used for control can significantly attenuate the loop interaction and hence improve the controller performance.

\section{1. $H_{\infty}$ filter preliminaries}

Measuring TCD and body lateral acceleration (relative to the track reference) however is not a practical solution, and a more appropriate solution is to estimate these quantities. A Kalman 
filter approach was presented in [6], while in this paper a $H_{\infty}$ filtering solution is proposed to deal with the issue of robustness to system uncertainty. Preliminaries on the $H_{\infty}$ filtering [15] are presented below.

The continuous-time system state space model is given below:

$$
\begin{aligned}
& \dot{x}=A x+B u+\Gamma w, \\
& y=C x+D u+v, \\
& z=L x,
\end{aligned}
$$

where $L$ is a user-defined matrix (the identity matrix for full state estimation) and $z$ is the vector containing the states to be estimated, and in general may also include certain linear combinations of the states. The following non-dimensional cost function is defined:

$$
J_{1}=\frac{\int_{0}^{\mathrm{T}}\|z-\hat{z}\|_{S}^{2} \mathrm{~d} t}{\|x(0)-\hat{x}(0)\|_{P_{0}-1}^{2}+\int_{0}^{\mathrm{T}}\left(\|w\|_{Q^{-1}}^{2}+\|v\|_{R^{-1}}^{2}\right) \mathrm{d} t},
$$

where $\hat{z}$ denotes the estimated states, and $\hat{x}(0)$ denotes the estimated state at time 0 . Vectors $w$ and $v$ are disturbances with unknown statistics (no restriction on the zero-mean). The following quantity is defined: $\|A\|_{B}^{2} \triangleq A^{\mathrm{T}} B A$, while $J_{1}$ is defined based on Game Theory concepts, the reader is referred to [15] for more details. The goal of $H_{\infty}$ filter design is to obtain an estimate $\hat{z}$ which minimises $J_{1}$, in general, the solution of the problem results in a state estimator that bounds the infinity norm of the transfer function from noise terms to the weighted state estimation error.[15] The direct minimisation of $J_{1}$ is not tractable, hence a performance bound is chosen such that:

$$
J_{1}<\frac{1}{\gamma}
$$

Here $\gamma$ is the user-specified bound (normally, $\gamma<1$ ). In addition, $P_{0}, Q, R$, and $S$ are positive-definite matrices chosen by the designer (in particular, these choices are governed by the specific problem under investigation). The estimator that solves the defined problem is given by

$$
\begin{aligned}
P(0) & =P_{0}, \\
\dot{P} & =A P+P A^{T}+Q-K C P+\gamma P L^{T} S L P, \\
K & =P C^{T} R^{-1}, \\
\dot{\hat{x}} & =A \hat{x}+B u+K(y-C \hat{x}-D u), \\
\hat{z} & =L \hat{x} .
\end{aligned}
$$

These equations are similar to the continuous-time Kalman filter equations except for the introduction of the $\gamma$ variable in the $\dot{P}$ equation. Increasing $\gamma$ results in the increase of gain $K$, which tends to make the estimator more responsive to measurements than the Kalman filter. This is a way of making the filter more robust to uncertainty in the system model. Setting $\dot{P}=0$ refers to the steady-state continuous-time $H_{\infty}$ filter, and matrix $P$ can be obtained by solving a Riccati equation.

\section{2. $H_{\infty}$ filter design for tilting railway vehicle system dynamics}

This section presents the design process of $H_{\infty}$ filter for the integrated tilt and active lateral secondary suspension control. The inputs to the $H_{\infty}$ filter are three measurements and two 
system inputs. The three measurements are: vehicle body roll gyroscope (cant information), body lateral accelerometer (for cant deficiency information) and vehicle body yaw gyroscope (required only for extra information on the curvature). The quantities, $\theta_{0}, \dot{\theta}_{0}, R^{-1}$ which are treated as system disturbances, are also required to be estimated, hence included in the state space model as states. Hence the system holds the following states:

$$
\dot{x}=\left[y_{v} \theta_{v} y_{b} \theta_{b} \dot{y}_{v} \dot{\theta}_{v} \dot{y}_{b} \dot{\theta}_{b} \theta_{r} y_{w} \dot{y}_{w} \theta_{m} \dot{\theta}_{m} \theta_{0} \dot{\theta}_{0} R^{-1}\right]^{\mathrm{T}} .
$$

Also two control inputs:

$$
u=\left[\theta_{m_{i}} F_{\mathrm{a}}\right]^{\mathrm{T}} .
$$

While the process noise is characterised by

$$
\omega=\left[\dot{R}^{-1} \ddot{\theta}_{0}\right]^{\mathrm{T}} .
$$

The algebraic Riccati equation presented in Equation (17) can be solved by using Matlab function 'care', and the estimation results are shown in Figure 4. These are the estimated TCD and estimated relative body lateral acceleration $\left(\ddot{y}_{v}\right)$ on curved track. The estimator successfully estimates all necessary quantities.

For the value selection of $L, Q, R$ and $S, L$ is equal to identity. $R$ and $Q$ were chosen based on design experience from the Kalman filter design. The choice of $S$ is critical for the $H_{\infty}$ design with the value chosen to weight more on quantities of interest (i.e the velocity of the body lateral movement $\left(\dot{y}_{v}\right)$, track cant angle variation rate $\left(\dot{\theta}_{0}\right)$, curve curvature $\left.R^{-1}\right)$. Tuning the parameters for the $H_{\infty}$ filter results in (note that further tuning is possible via heuristics methods, e.g. Genetic Algorithms):

$$
\begin{aligned}
& R=\operatorname{diag}\left(1.1 \times 10^{-3}, 1.4 \times 10^{-6}, 1 \times 10^{-6}\right), \\
& Q=\operatorname{diag}\left(8.33 \times 10^{-6}, 2.32 \times 10^{-3}\right), \\
& L=\operatorname{diag}(1,1,1,1,1,1,1,1,1,1,1,1,1,1,1,1), \\
& S=\operatorname{diag}(10,10,10,10,10000,10,10,10,10,10,10,10,10,10000,10000,10), \\
& \gamma=0.2 .
\end{aligned}
$$

\subsection{Parametric uncertainty test}

The robustness test of the $H_{\infty}$ filter with respect to parametric uncertainty is performed in this section compared to Kalman-Bucy filter. The same $Q$ and $R$ values as those used for the $H_{\infty}$ filter are chosen for the Kalman filter:

$$
\begin{aligned}
& R=\operatorname{diag}\left(1.1 \times 10^{-3}, 1.4 \times 10^{-6}, 1 \times 10^{-6}\right), \\
& Q=\operatorname{diag}\left(8.33 \times 10^{-6}, 2.32 \times 10^{-3}\right) .
\end{aligned}
$$

Test cases:

- Test case 1: The mass of vehicle body varies from $10,000 \mathrm{~kg}$ to $24,000 \mathrm{~kg}$ due to the variation of the vehicle load (nominal value is $16,000 \mathrm{~kg}$ ). For completeness, and realistic test case, it is combined with a corresponding variation of the body roll inertia increasing from $19,000 \mathrm{~kg} \mathrm{~m}^{2}$ to $22,325 \mathrm{~kg} \mathrm{~m}^{2}$ :

$$
m=m_{v}\left(1+p_{m} \delta_{m}\right), \quad i_{v r}=i_{v r}\left(1+p_{i_{v r}} \delta_{i_{v r}}\right)
$$




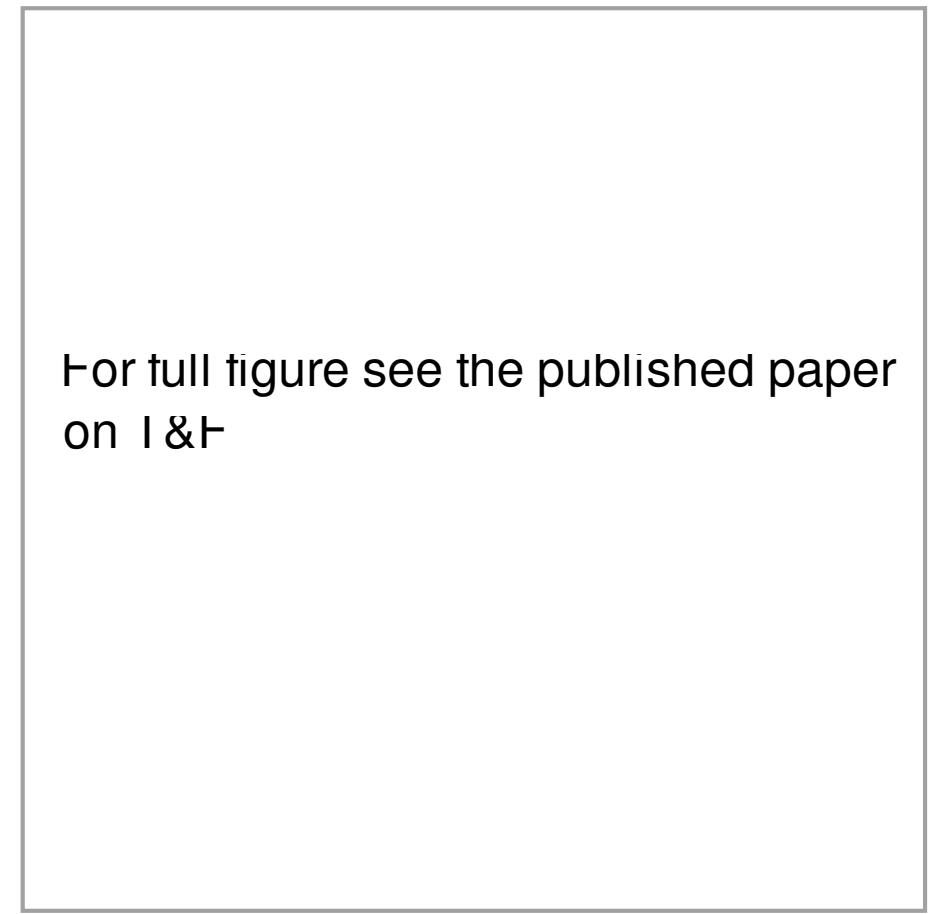

Figure 4. $\quad H_{\infty}$ filter estimation results. (a) True cant deficiency, (b) Vehicle body lateral acceleration (relative to track).

where $\delta_{m}=0.2, p_{m} \in[0,7] ; p_{i_{v r}}=0.025, \delta_{i_{v r}} \in[0,7]$. Figure 5 shows the RMS value of the estimation error and maximum estimation error based on varying the mass and roll inertia for the body lateral acceleration estimation, respectively. The test results illustrate that both Kalman filter and $H_{\infty}$ filter can work well in certain regions, but the $H_{\infty}$ filter approach provides more robustness against wide variation of the vehicle body mass (Figure 5). 
This is an Author's Original Manuscript of an article published by Taylor \& Francis Group in Vehicle System Dynamics: International Journal of Vehicle Mechanics and Mobility available online: http://www.tandfonline.com/doi/abs/10.1080/00423114.2014.901540\#.

(a)

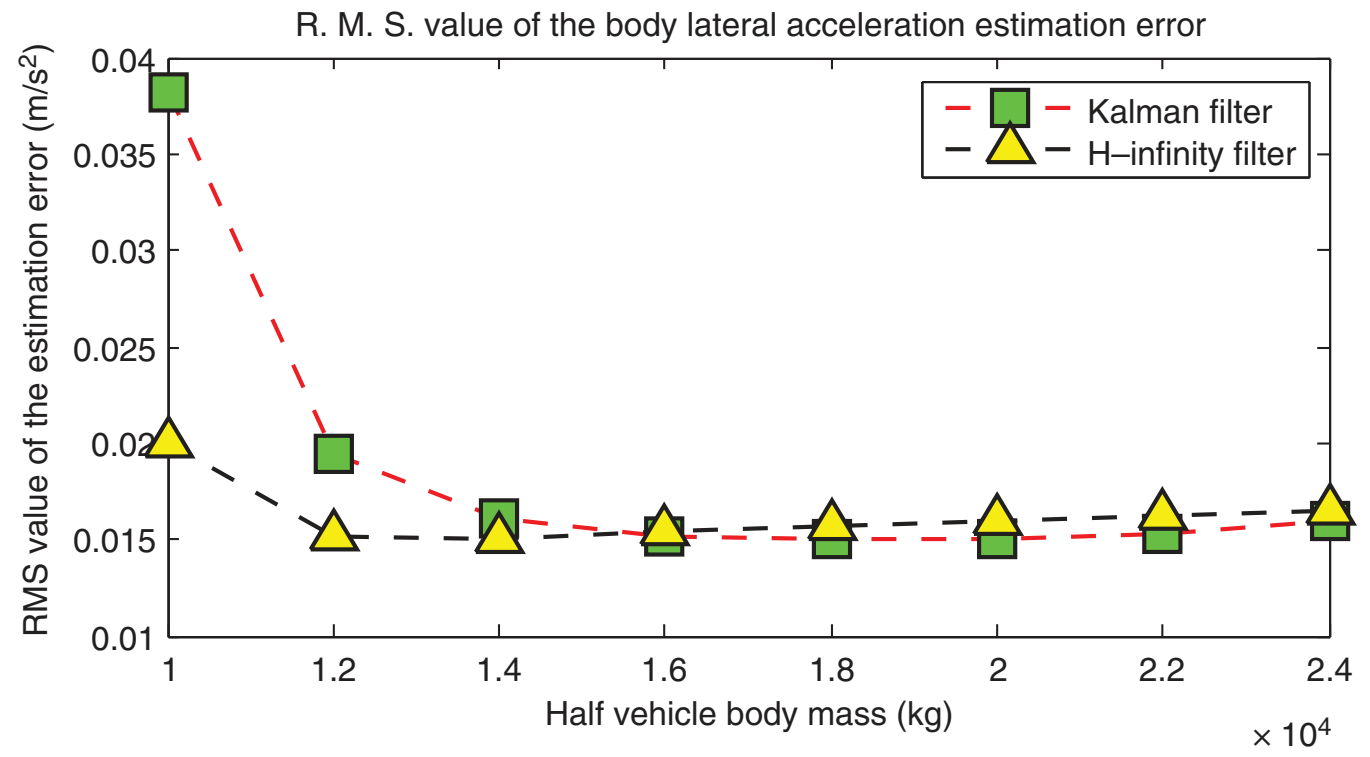

(b)

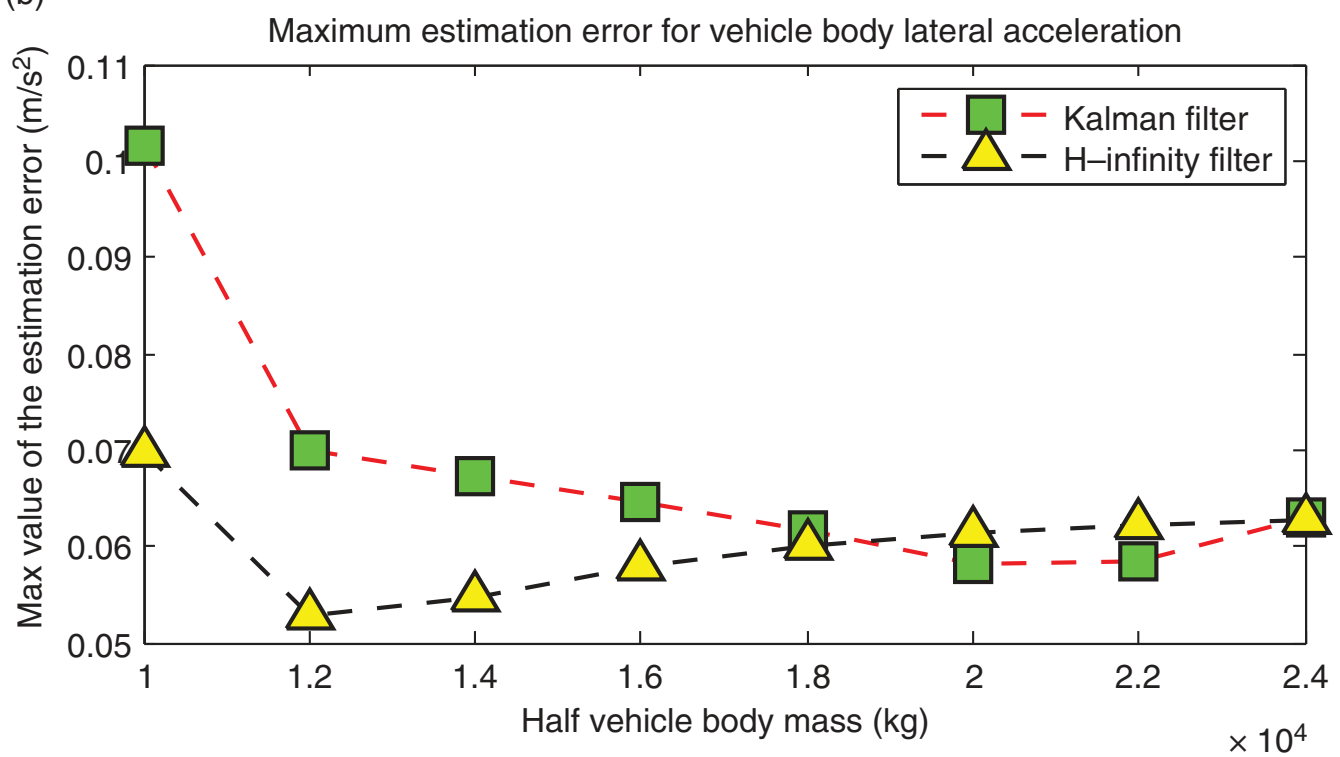

Figure 5. Body lateral acceleration estimation error with respect to parametric uncertainties (test case 1), the nominal value (body mass): 16,000 kg. (a) RMS value of the estimation error. (b) Maximum value of the estimation error.

- Test case 2: The parameter for the lateral secondary spring decreases from $130 \mathrm{kN} / \mathrm{m}$ to $20 \mathrm{kN} / \mathrm{m}$ (nominal value is $100 \mathrm{kN} / \mathrm{m}$, the worst case test here), i.e.

$$
k_{s y}=k_{s y}-p_{k_{s y}} \delta_{k_{s y}}
$$

where $\delta_{k_{s v}}=5000, p_{k_{s v}} \in[0,21]$. The test results (shown in Figure 6) illustrate the improved robustness of the $H_{\infty}$ filter when the spring coefficient is less than $45 \mathrm{kN} / \mathrm{m}$.

\subsection{EBD control configuration}

The control configuration of EBD control is given in Figure 7. The skyhook damping control [13] is employed for the lateral actuator while proportional-integral-derivative (PID) control is used for the tilt control. The detailed simulation results were discussed in [6], but a short summary is presented here. As shown in Figure 8, the performance of the $H_{\infty}$ filter-based 


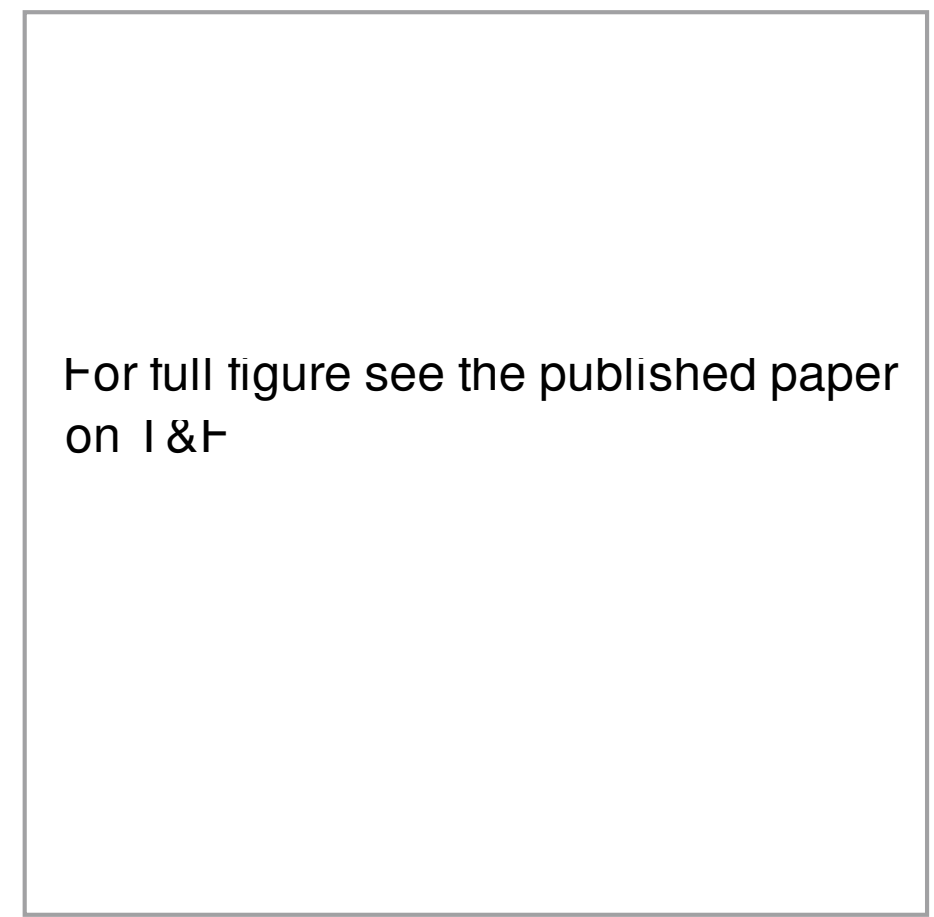

Figure 6. Body lateral acceleration estimation error with respect to parametric uncertainties (test case 2), the nominal value (spring coefficient): $100 \mathrm{kN} / \mathrm{m}$. (a) RMS value of the estimation error. (b) Maximum value of the estimation error.

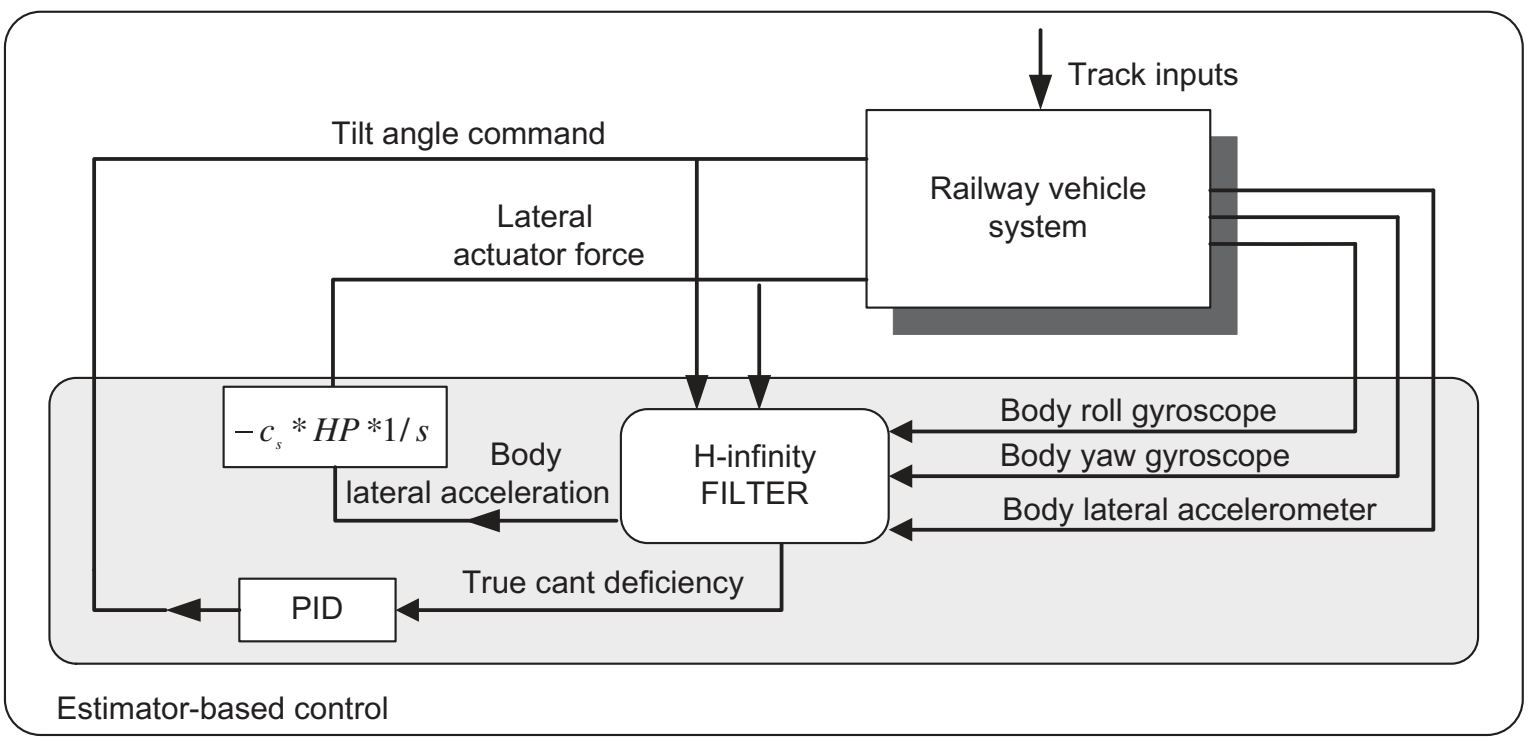

Figure 7. Estimator-based decoupling control configuration. 
This is an Author's Accepted Manuscript of an article published by Taylor \& Francis Group in Vehicle System Dynamics: International Journal of Vehicle Mechanics and Mobility available online: http://www.tandfonline.com/doi/abs/10.1080/00423114.2014.901540\#.

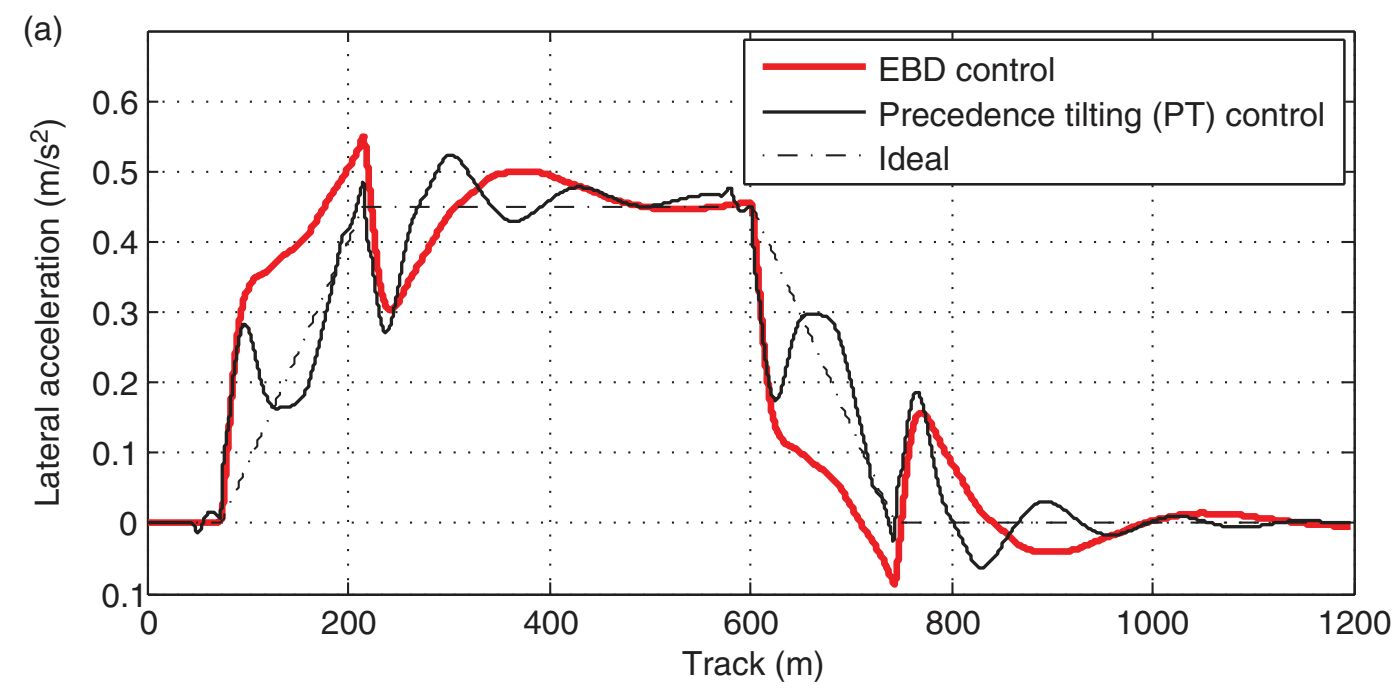

(b)

\section{Complete tigure see the published paper on I\&}

Figure 8. Simulation results for EBD control. (a) Measured body lateral acceleration. (b) Tilt angle.

Table 1. Control system assessment for EBD control at $58(\mathrm{~m} / \mathrm{s})$.

\begin{tabular}{lcc}
\hline & $E B D$ & $P T$ \\
\hline $\begin{array}{l}\text { Deterministic (curved track) } \\
\text { Lateral acceleration }\end{array}$ & \\
$\quad$ Steady-state (\%g) & 4.6 & 4.6 \\
RMS deviation error (\%g) & 0.89 & 0.73 \\
Peak value (\%g) & 5.6 & 5 \\
Roll gyroscope & & \\
$\quad$ RMS deviation (rad/s) & 0.014 & 0.015 \\
Peak value (rad/s) & 0.11 & 0.11 \\
Peak jerk level (\%g/s) & 3.82 & 3.02 \\
$P_{c t}(P$-factor) & & \\
$\quad$ Standing (\% of passengers) & 23.8 & 20.6 \\
Seated (\% of passengers) & 4.9 & 3.7 \\
$\quad$ Stochastic (straight track) & & \\
Passenger comfort & & \\
RMS passive (\%g) & 3.24 & 3.24 \\
$\quad$ RMS active (\%g) & 1.63 & 2.29 \\
Degradation (\%) & -49.69 & -28.6 \\
\hline
\end{tabular}


EBD control is close to conventional precedence tilting (PT) control,[4] hence quite close to the so-called 'ideal tilt' action.[12] As listed in Table 1, the RMS deviation error of EBD control for the lateral acceleration is $0.89 \% \mathrm{~g}$, which is close to the value of the PT control $(0.73 \% \mathrm{~g})$. Also, the $P_{c t}$ value for seated passengers $(4.9 \% \mathrm{~g})$ of the EBD control is close to the value for the PT control $(3.7 \% \mathrm{~g})$. The trend for the standing $P_{c t}$ values is not only similar, but also the lateral ride quality is significantly better due to the active lateral control.

\section{Conclusion}

In this paper, the integrated tilt and active lateral secondary suspension control for high-speed tilting trains is discussed with emphasis on estimator-based control, i.e. the $H_{\infty}$ filter-based robust estimation for estimating vehicle body lateral acceleration and TCD. Simulation results illustrate the efficacy of the $H_{\infty}$ filter providing enhanced robustness to system parameter variations, thus enhanced performance of the estimator-based control system. Note that, the discussion on the robust state estimation in this paper can be further extended to a fault tolerant framework.

This study has identified a practical, robust solution for achieving effective tilting control without the need for the additional complexity of a precedence tilt control strategy.

\section{References}

[1] Goodall RM. Tilting trains and beyond - the future for active railway suspensions: part 1 improving passenger comfort. Comput Control Eng J. 1990;10:153-160.

[2] Persson R, Goodall RM, Sasak K. Carbody tilting - technologies and benefits. Veh Syst Dyn. 2009;47:949-981.

[3] Hauser G. TILTRONIX ${ }^{\mathrm{TM}}$, anticipative tilt control. Le Rail 4th Conference; Paris, France; 2006.

[4] Zolotas AC, Goodall RM, Halikias GD. Recent results in tilt control design and assessment of high speed railway vehicles. IMECHE J Rail Rapid Transit. 2007;221:291-312.

[5] Zolotas AC, Goodall RM, Halikias GD. New control strategies for tilting trains. Veh Syst Dyn. 2002;37:171182.

[6] Zhou R, Zolotas AC, Goodall RM. Integrated tilt with active lateral secondary suspension control for high speed railway vehicles. Mechatronics. 2011;21:1108-1122.

[7] Li H. Measuring systems for active steering of railway vehicles [dissertation]. Loughborough University; 2001.

[8] Bruni S, Goodall RM, Mei TX, Tsunashima H. Control and monitoring for railway vehicle dynamics. Veh Syst Dyn. 2007;45:743-779.

[9] Satria M, Best MC. State estimation of vehicle handling dynamics using non-linear robust extended adaptive Kalman filter. Veh Syst Dyn. 2004;41:103-112.

[10] Pratt I. Active suspension applied to railway trains [dissertation]. Loughborough University of Technology; 1996.

[11] ISO. Mechanical vibration and shock - Evaluation of human exposure to whole body vibration - part 1: general requirements. ISO 2631-1.2: 1997(E). Geneva: ISO.

[12] Goodall RM, Zolotas A, Evans J. Assessment of the performance of tilt system controllers. The railway conference at Railtex'00; NEC Birminghum, UK; November 2000.

[13] Li H, Goodall RM. Linear and non-linear skyhook damping control laws for active railway suspensions. Control Eng Pract. 1999;7:843-850.

[14] Zhou R, Zolotas AC, Goodall RM. 9 DOF railway vehicle modeling and control for the integrated tilting bolster with active lateral secondary suspension. Proceedings of the UKACC international conference on control; Coventry, UK; September 2010.

[15] Simon D. Optimal state estimation: Kalman, H-infinity, and nonlinear approaches. 1st ed. Wiley, New York; 2006. 


\section{Appendix 1. Notation employed in the modelling}

$y_{v}, y_{b}, y_{0} \quad$ lateral displacement of body, bogie, and track

$\theta_{v}, \theta_{b}, \delta_{a}$ roll displacement of body, bogie, and actuator

$\theta_{0}, R \quad$ track cant, curve radius

$\theta_{r} \quad$ airspring reservoir roll defection

$y_{w} \quad$ lateral displacement of wheel set

$\theta_{m i} \quad$ ideal mechanism roll input

$\theta_{m}, \dot{\theta}_{m} \quad$ actuator mechanism roll position and rate

$v \quad$ vehicle forward speed

$m_{v} \quad$ half body mass, $16,000 \mathrm{~kg}$

$m_{b} \quad$ bogie mass, $3680 \mathrm{~kg}$

$i_{v r} \quad$ half-body roll inertia, $20,000 \mathrm{~kg} \mathrm{~m}^{2}$

$i_{b r} \quad$ bogie roll inertia, $2500 \mathrm{~kg} \mathrm{~m}^{2}$

$k_{a z} \quad$ airspring area stiff., $210,500 \mathrm{~N} / \mathrm{m}$

$k_{s z} \quad$ airspring series stiff., $300,000 \mathrm{~N} / \mathrm{m}$

$k_{r z} \quad$ airspring reserv. stiff., $201,000 \mathrm{~N} / \mathrm{m}$

$c_{r z} \quad$ airspring reserv. damp., 20,000 (Ns)/m

$k_{s y} \quad$ secondary lateral stiff., $100,000 \mathrm{~N} / \mathrm{m}$

$k_{v r} \quad$ anti-roll bar stiff./bogie, 1,500,000 (Nm)/rad

$c_{v r} \quad$ primary vertical damp., $18,200(\mathrm{Ns}) / \mathrm{m}$

$k_{p z} \quad$ primary vertical stiff., $1,600,000 \mathrm{~N} / \mathrm{m}$

$c_{p z} \quad$ primary vertical damp., $20,000(\mathrm{Ns}) / \mathrm{m}$

$k_{p y} \quad$ primary lateral stiff., $18,000,000 \mathrm{~N} / \mathrm{m}$

$c_{p y} \quad$ primary lateral damp., $20,000(\mathrm{Ns}) / \mathrm{m}$

$d_{1} \quad$ airspring semi-spacing, $0.835 \mathrm{~m}$

$d_{2} \quad$ primary vert. suspen. semi-spacing, $1.00 \mathrm{~m}$

$h_{1} \quad$ secondary later. suspen. height(body cog), $0.844 \mathrm{~m}$

$h_{2} \quad$ secondary later. suspen. height(bogie cog), $0.252 \mathrm{~m}$

$h_{3} \quad$ primary later. suspen. height(bogie cog), $0.194 \mathrm{~m}$

$h_{g 1} \quad$ bogie c.o.g. height(rail level), $1.696 \mathrm{~m}$

$h_{g 2} \quad$ body c.o.g. height(rail level), $0.60 \mathrm{~m}$

$h_{m t} \quad$ mechanism c.o.g. vertical separation from effective tilt center, $0.60 \mathrm{~m}$ 